\title{
Body composition and arsenic metabolism: a cross-sectional analysis in the Strong Heart Study
}

\author{
Matthew O Gribble ${ }^{1 *}$, Ciprian M Crainiceanu ${ }^{2}$, Barbara V Howard ${ }^{3,4}$, Jason G Umans ${ }^{3,4}$, Kevin A Francesconi ${ }^{5}$, \\ Walter Goessler ${ }^{5}$, Ying Zhang ${ }^{6}$, Ellen K Silbergeld ${ }^{7}$, Eliseo Guallar ${ }^{1,8}$ and Ana Navas-Acien ${ }^{1,7}$
}

\begin{abstract}
Objective: The objective of this study was to evaluate the association between measures of body composition and patterns of urine arsenic metabolites in the 1989-1991 baseline visit of the Strong Heart Study, a cardiovascular disease cohort of adults recruited from rural communities in Arizona, Oklahoma, North Dakota and South Dakota.

Methods: We evaluated 3,663 Strong Heart Study participants with urine arsenic species above the limit of detection and no missing data on body mass index, \% body fat and fat free mass measured by bioelectrical impedance, waist circumference and other variables. We summarized urine arsenic species patterns as the relative contribution of inorganic (iAs), methylarsonate (MMA) and dimethylarsinate (DMA) species to their sum. We modeled the associations of $\%$ arsenic species biomarkers with body mass index, \% body fat, fat free mass, and waist circumference categories in unadjusted regression models and in models including all measures of body composition. We also considered adjustment for arsenic exposure and demographics.

Results: Increasing body mass index was associated with higher mean \% DMA and lower mean \% MMA before and after adjustment for sociodemographic variables, arsenic exposure, and for other measures of body composition. In unadjusted linear regression models, \% DMA was $2.4(2.1,2.6) \%$ higher per increase in body mass index category $\left(<25, \geq 25 \&<30, \geq 30 \&<35, \geq 35 \mathrm{~kg} / \mathrm{m}^{2}\right)$, and \% MMA was $1.6(1.4,1.7) \%$ lower. Similar patterns were observed for \% body fat, fat free mass, and waist circumference measures in unadjusted models and in models adjusted for potential confounders, but the associations were largely attenuated or disappeared when adjusted for body mass index.
\end{abstract}

Conclusion: Measures of body size, especially body mass index, are associated with arsenic metabolism biomarkers. The association may be related to adiposity, fat free mass or body size. Future epidemiologic studies of arsenic should consider body mass index as a potential modifier for arsenic-related health effects.

Keywords: American Indians, Arsenic, Arsenic metabolism, Arsenic species, Obesity, Body mass index, Strong Heart Study

\section{Background}

Inorganic arsenic (iAs) is a known human carcinogen [1]. Major sources of exposure to inorganic arsenic for the general population include contaminated water and food [2-5]. After exposure, iAs is methylated [6] and then eliminated in urine as iAs ( 10-30\%), monomethylarsonate (MMA, 10-20\%) and dimethylarsinate (DMA, 60-80\%) [7-12]. Variation in the pattern of urine metabolites has been related to arsenic-associated outcomes including

\footnotetext{
* Correspondence: mgribble@jhsph.edu

${ }^{1}$ Department of Epidemiology and Welch Center for Prevention, Epidemiology and Clinical Research, Johns Hopkins University Bloomberg School of Public Health, 615 N. Wolfe Street Office W7513D, Baltimore MD 21205MD, USA Full list of author information is available at the end of the article
}

skin lesions [13-15], cancers [16-22] and cardiovascular diseases [23,24]. This may be due to urine arsenic species patterns reflecting differential bioavailability across individuals [25-27] of arsenic species with distinct toxicities [28-31]. Genetic variants partly determine the pattern of urine arsenic metabolites [32]. The main enzyme identified in arsenic methylation reactions is arsenic (III) methyltransferase [33-35] but other enzymes, cofactors, and transporters may also contribute [32].

Non-genetic determinants of arsenic metabolism may include sex, smoking, alcohol intake and nutritional status including dietary folate and vitamin B $[36,37]$. Recently, increased body mass index has been related to

\section{Biomed Central}


higher \%DMA and lower \%MMA in urine in populations from Northern Mexico, Central Europe, and Bangladesh $[10,38,39]$, although other studies in Bangladesh have been inconsistent $[13,40]$. In a study of 303 adolescents from Taiwan, adolescents with obesity had higher \%MMA and lower \%DMA compared to adolescents without obesity [41], but the differences were not statistically significant. Body mass index is an imperfect measure of adiposity, as it reflects both adipose tissue and fat free mass [42]. Other measures of adiposity or body composition were not evaluated in these studies. Studying the relationships of arsenic metabolism with other measures of adiposity and body composition, such as waist circumference (a measure of central adiposity), body fat and fat free mass, might help to distinguish whether associations are with adiposity or with fat free body mass.

The Strong Heart Study (SHS) is a large rural cohort study with standardized measures of cardiovascular risk factors including multiple measures of body size and body composition (body mass index, percent body fat and fat free mass measured by bioelectrical impedance, and waist circumference). Participants also provided a spot urine sample, allowing for the measurement of arsenic metabolites. The objective of this study was to evaluate the cross-sectional association of adiposity with the pattern of urine arsenic metabolites in SHS participants in 1989-1991.

\section{Methods}

\section{Study population}

The recruitment and examination protocols of the SHS have been described in detail [43]. Briefly, the tribal rolls from 13 American Indian tribes and communities were used to recruit the study population, aiming for 1,500 participants at each study center (Arizona, Oklahoma, and North/South Dakota). A total of 4,549 adults were recruited in 1989-1991. All participants provided informed consent, and all study protocols were approved by institutional and Indian Health Service institutional review boards as well as by the participating tribes.

Total urine arsenic and arsenic species, including iAs, MMA and DMA were measured in 3,974 participants with sufficient urine sample available. For this study, we further excluded one participant missing iAs measurements and participants with iAs $(n=210)$, MMA $(n=29)$ or DMA $(n=1)$ below the limit of detection. We also excluded participants missing data on body mass index $(n=16)$, percent body fat $(n=53)$, waist circumference $(n=5)$, education $(\mathrm{n}=4)$, drinking status (current/ever/never; $\mathrm{n}=9$ ) or total urine arsenic $(\mathrm{n}=1)$, leaving 3,663 participants for the analysis. The participants included in the analyses were similar to the overall study population with respect to sociodemographic characteristics (Additional file 1: Appendix 1).

\section{Measures of body composition}

Participants were interviewed and physically examined by centrally trained staff according to a standardized protocol [43-45]. Participants were examined in the morning after a 12-hour overnight fast, which included instruction not to eat breakfast the morning of the visit to the exam, and to eat or drink nothing but water after 9:00 the previous evening $[43,45]$. Each study center had a designated anthropometry supervisor. Height was measured standing in centimeters rounded to the nearest integer, and weight was measured in kilograms using a scale that was re-zeroed each day and calibrated against a known $50 \mathrm{lb}$ weight every month or whenever the scale was moved. Body mass index was calculated by dividing weight in kilograms by height in meters squared. Waist circumference at umbilicus was measured supine in centimeters rounded to the nearest integer. The bioelectric impedance was measured supine on the right side, unless amputated, using Impedance Meter Model \# B1A101 (RJL Equipment Company) [45]. For the impedance measurements, participants were checked by examiners to confirm they had not exercised vigorously for the past 12 hours, had not consumed alcohol in the past 24 hours, and were not dehydrated [45]. We estimated fat free mass and percentage of body fat fat freeby equations based on total body water validated in American Indian populations [46,47].

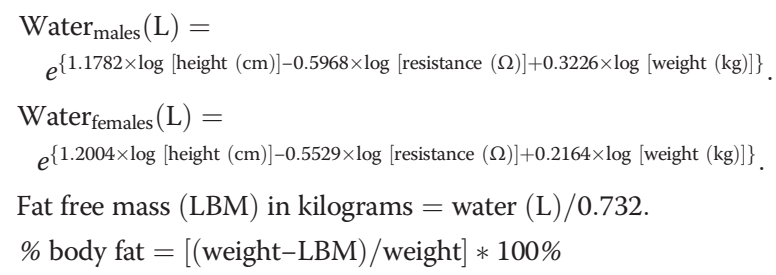

\section{Urine arsenic metabolites}

Spot urine samples collected at the 1989-91 baseline visit were stored at $-80^{\circ} \mathrm{C}$ at the Penn Medical Laboratory, MedStar Health Research Institute (Hyattsville, MD and Washington, DC, USA) (Lee et al. 1990). In 2009, aliquots of up to $1.0 \mathrm{~mL}$ from each participant were shipped to the Trace Element Laboratory of the Institute of Chemistry-Analytical Chemistry, Karl Franzens University (Graz, Austria) for trace element analysis [48]. The laboratory uses calibration blanks and calibration standards, calibration checks, sample spikes and blanks, NIES No 18 Human urine, and in-house urine reference samples for quality control/quality assurance purposes. Concentrations of iAs, MMA, and DMA were determined by anion-exchange high performance liquid chromatography (HPLC; Agilent 1100, Agilent Technologies, Waldbronn, Germany) coupled to inductively coupled plasma mass spectrometry (ICPMS) (Agilent 7700x). The limits of detection were $0.1 \mu \mathrm{g} / \mathrm{L}$ for iAs, MMA, and DMA. The 
inter-assay coefficients of variation for iAs, MMA, and DMA for the in-house reference urine specimens were $6.0 \%, 6.5 \%$, and $5.9 \%$.

\section{Statistical analysis methods}

To evaluate arsenic metabolism, we calculated \%iAs, \%MMA, and \%DMA as the relative contribution of iAs, MMA, or DMA to their sum, multiplied by 100 , and analyzed the association of each \% species biomarker with each measure of body composition (body mass index, percent body fat, fat free mass and waist circumference) separately using linear regression models. Body mass index was categorized as $<25, \geq 25$ and $<30, \geq 30$ and $<35$ and $\geq 35 \mathrm{~kg} / \mathrm{m}^{2}$. Percent body fat, fat free mass and waist circumference were categorized as sex-specific quartiles. Adjusted models accounted for study region, age ( $<55$ and $\geq 55$ years), sex, smoking status (current/ever/ never), drinking status (current/ever/never), high school completion (yes/no), and quartiles of total urine arsenic adjusted for specific gravity. To obtain quartiles of total urine arsenic adjusted for specific gravity (a proxy for urine dilution of the spot urine sample), we fit linear regressions of measured urine arsenic on specific gravity and took quartiles of the residuals. We considered sensitivity analyses adjusting for restricted cubic splines of continuous variables (e.g. age, specific gravity-corrected arsenic) with consistent findings (data not shown). In addition to evaluating each measure of body composition separately, we also contrasted the four measures of body composition in models with multiple measures of body composition. Because both arsenic metabolism and adiposity differ by sex, we evaluated the association between \% arsenic species and measures of body composition stratified by sex, with consistent findings (data not shown). Because approximately half of the study population had diabetes [49], we also evaluated the association between \% arsenic species and adiposity by diabetes status with consistent findings (data not shown).

The \%iAs, \%MMA and \%DMA are skewed distributions but not log-normal (Additional file 2: Appendix 2), resulting in a poor fit for linear regression models. In a sensitivity analysis, we used generalized gamma regression [50] to evaluate the association between urine arsenic metabolism biomarkers with measures of body composition. The generalized gamma distribution is characterized by a location parameter $\beta$ that defines the position of the distribution median, a scale parameter $\sigma$ that reflects the distribution's spread, and a shape parameter $\mathrm{K}$ that defines the family of the distribution (lognormal, gamma, Weibull, etc.). We also conducted a second sensitivity analysis using beta regression for each \% arsenic species (divided by 100) since these biomarkers are proportion data [51] and Dirichlet regression, a multivariate modification of the beta regression that models all \% arsenic species as a set that must sum to one [52]. All statistical analyses were performed in Stata/ SE 11.2, augmented with $<$ dirifit $>$ and $<$ betafit $>$ contributed packages.

\section{Results}

Mean (SD) body mass index, percent body fat, fat free mass and waist circumference were $30.9(6.3) \mathrm{kg} / \mathrm{m}^{2}$, $36.2(9.1) \%, 53(11) \%$, and $105.4(14.7) \mathrm{cm}$, respectively. The Spearman correlation coefficient was 0.66 between body mass index and percent body fat, 0.36 between body mass index and fat free mass, 0.88 between body mass index and waist circumference, -0.35 between percent body fat and fat free mass, and 0.63 between percent body fat and waist circumference (Table 1).

Median (IQR) were $7.9(5.6,11.0) \%$ for \%iAs, 13.9 $(10.8,17.5) \%$ for MMA and 77.8 (72.0, 82.7)\% for \%DMA (Table 2). The \%iAs and \%MMA biomarkers were moderately positively correlated (Spearman correlation coefficient 0.47), while \%DMA was strongly negatively correlated with \%iAs and \%MMA (Spearman correlation coefficients -0.82 and -0.87 , respectively) (Table 1 ). Median \%iAs was higher in men, younger participants, current smokers, and current drinkers, and lower in Oklahoma (Table 2). Median \%MMA was higher in men, older participants, participants from North and South Dakota, and current smokers. Median \%DMA was lower in men, participants from North and South Dakota, current smokers and current drinkers.

In crude analyses, \%iAs and \%MMA were inversely related to body mass index (Spearman correlations -0.16 , -0.32 , respectively), percent body fat $(-0.25,-0.35)$, and waist circumference $(-0.15,-0.29)$, and positively related to fat free mass $(0.15,0.07)$ (Table 1$)$. \%DMA was positively related to body mass index $(0.28), \%$ body fat $(0.35)$ and waist circumference (0.27), and inversely related to fat free mass $(-0.12)$ (Table 1). All these Spearman correlations were significant at $\mathrm{p}<0.0001$. The correlations between fat free mass and \%iAs, \%MMA and \%DMA were confounded by sex, and in analyses using sex-specific quartiles of fat free mass the crude associations were in the same direction as for the other measures of body composition (Table 3, Table 4).

Increasing body mass index categories remained associated with lower mean \%iAs $(-1.7$, comparing $\mathrm{BMI} \geq 35$ to $\mathrm{BMI}<25$, with $95 \% \mathrm{CI}:-2.2,-1.2)$ and \%MMA $(-4.0$, 95\% CI: $-4.5,-3.5)$ and higher mean \%DMA $(+5.7$, 95\% CI: 4.8, 6.5) after adjustment for arsenic exposure and demographics (Table 3). Similar dose responses were observed for \% body fat, fat free mass, and waist circumference when analyzed in separate models. In models adjusting for other measures of body composition at the same time, higher body mass index remained associated with lower \%iAs and \%MMA and higher \%DMA. For 
Table 1 Spearman correlation coefficients of body composition measures and arsenic metabolism biomarkers

\begin{tabular}{|c|c|c|c|c|c|c|c|}
\hline & Body mass index & $\%$ Body fat & Fat free body mass & Waist circumference & $\%$ iAs & $\%$ MMA & $\%$ DMA \\
\hline Body mass index & 1.00 & & & & & & \\
\hline$\%$ Body fat & 0.66 & 1.00 & & & & & \\
\hline Fat free body mass & 0.36 & -0.35 & 1.00 & & & & \\
\hline Waist circumference & 0.88 & 0.63 & 0.33 & 1.00 & & & \\
\hline$\%$ iAs & -0.16 & -0.25 & 0.15 & -0.16 & 1.00 & & \\
\hline$\%$ MMA & -0.32 & -0.35 & 0.07 & -0.29 & 0.47 & 1.00 & \\
\hline$\%$ DMA & 0.29 & 0.35 & -0.12 & 0.27 & -0.82 & -0.87 & 1.00 \\
\hline
\end{tabular}

$\mathrm{N}=3,663$ participants.

waist circumference, the association with \% arsenic species disappeared when adjusted for body mass index but remained when adjusting for \% body fat and fat free mass. For \% body fat and fat free mass, the associations disappeared when adjusting for body mass index or waist circumference, and were attenuated when adjusting for each other.

Our sensitivity analyses using generalized gamma regression, beta regression and Dirichlet regression were consistent with the findings obtained by linear regression

Table 2 Arsenic metabolite proportions by participant characteristics

\begin{tabular}{|c|c|c|c|c|c|c|c|}
\hline Participants & $\mathrm{N}(\%)$ & $\%$ iAs median (IQR) & $P$ value & $\%$ MMA median (IQR) & $P$ value & $\%$ DMA median (IQR) & $P$ value \\
\hline Overall & 3,663 & $7.9(5.6,11.0)$ & & $13.9(10.8,17.5)$ & & $77.8(72.0,82.7)$ & \\
\hline \multicolumn{8}{|l|}{ Sex } \\
\hline Female & $2,157(58.9)$ & $7.0(5.0,10.0)$ & & $13.0(10.0,16.0)$ & & $79.7(74.7,84.1)$ & \\
\hline Male & $1,506(41.1)$ & $9.4(6.7,12.9)$ & $<0.001$ & $15.7(12.4,19.4)$ & $<0.001$ & $74.5(67.9,80.0)$ & $<0.001$ \\
\hline \multicolumn{8}{|l|}{ Age } \\
\hline$<55$ years & $1,836(50.1)$ & $8.5(6.0,11.5)$ & & $13.9(10.8,17.6)$ & & $77.3(71.7,82.2)$ & \\
\hline$\geq 55$ and $<65$ years & $1,190(32.5)$ & $7.6(5.4,10.5)$ & & $13.6(10.7,17.3)$ & & $78.6(72.4,83.3)$ & \\
\hline$\geq 65$ years & $637(17.4)$ & $7.1(5.0,9.7)$ & $<0.001$ & $14.6(11.2,17.8)$ & 0.03 & $78.2(72.4,82.7)$ & 0.005 \\
\hline \multicolumn{8}{|l|}{ BMI } \\
\hline$<25 \mathrm{~kg} / \mathrm{m}^{2}$ & $557(15.2)$ & $9.1(6.2,12.4)$ & & $16.7(13.2,20.3)$ & & $74.4(67.3,79.6)$ & \\
\hline$\geq 25$ and $<30 \mathrm{~kg} / \mathrm{m}^{2}$ & $1,236(33.7)$ & $8.4(5.8,11.5)$ & & $15.0(11.6,18.5)$ & & $76.3(70.5,81.3)$ & \\
\hline$\geq 30$ and $<35 \mathrm{~kg} / \mathrm{m}^{2}$ & $1,057(28.9)$ & $7.5(5.5,10.5)$ & & $13.3(10.5,16.5)$ & & $78.9(73.3,83.3)$ & \\
\hline$\geq 35 \mathrm{~kg} / \mathrm{m}^{2}$ & $813(22.2)$ & $7.1(5.2,9.8)$ & $<0.001$ & $11.9(9.1,14.8)$ & $<0.001$ & $80.8(75.9,85.3)$ & $<0.001$ \\
\hline \multicolumn{8}{|l|}{ Study center } \\
\hline Arizona & $1,281(35.0)$ & $8.6(6.1,11.5)$ & & $13.3(10.4,16.4)$ & & $78.1(72.6,82.5)$ & \\
\hline Oklahoma & $1,141(31.2)$ & $6.6(4.6,9.3)$ & & $13.4(10.2,16.7)$ & & $79.6(74.0,84.3)$ & \\
\hline North or South Dakota & $1,241(33.9)$ & $8.4(6.1,11.7)$ & $<0.001$ & $15.3(11.9,19.2)$ & $<0.001$ & $75.9(69.6,81.1)$ & $<0.001$ \\
\hline \multicolumn{8}{|l|}{ Smoking status } \\
\hline Never & $1,177(32.1)$ & $7.4(5.3,10.1)$ & & $13.3(10.1,16.3)$ & & $79.0(73.9,83.5)$ & \\
\hline Former & $1,240(33.9)$ & $7.6(5.4,10.5)$ & & $13.6(10.8,17.1)$ & & $78.4(72.8,83.2)$ & \\
\hline Current & $1,246(34.0)$ & $9.0(6.1,12.2)$ & $<0.001$ & $15.2(11.6,19.0)$ & $<0.001$ & $75.8(69.2,81.3)$ & $<0.001$ \\
\hline \multicolumn{8}{|l|}{ Drinking status } \\
\hline Never & $575(15.7)$ & $7.1(5.2,9.8)$ & & $13.5(10.6,16.6)$ & & $79.2(73.6,83.3)$ & \\
\hline Former & $1,517(41.4)$ & $7.6(5.4,10.8)$ & & $13.9(10.8,17.3)$ & & $78.1(72.4,83.0)$ & \\
\hline Current & $1,571(42.9)$ & $8.4(5.9,11.7)$ & $<0.001$ & $14.2(10.8,18.0)$ & 0.008 & $77.0(70.8,82.2)$ & $<0.001$ \\
\hline \multicolumn{8}{|l|}{ High school completion } \\
\hline Yes & $1,793(47.5)$ & $7.7(5.5,10.8)$ & & $13.9(10.7,17.3)$ & & $78.0(72.3,83.0)$ & \\
\hline No & $1,924(52.5)$ & $8.3(5.7,11.2)$ & 0.002 & $13.9(10.8,17.7)$ & 0.28 & $77.6(71.7,82.5)$ & 0.03 \\
\hline
\end{tabular}

*P values are from Kruskal-Wallis tests.

Arsenic $\%$ species must sum to $100 \%$ within each person. 
Table 3 Difference $(95 \% \mathrm{CI})$ of mean \% arsenic species in urine by body composition measure categories

\begin{tabular}{|c|c|c|c|c|c|c|}
\hline & \multicolumn{2}{|c|}{$\%$ iAs } & \multicolumn{2}{|c|}{$\%$ MMA } & \multicolumn{2}{|c|}{ \% DMA } \\
\hline & Unadjusted & Adjusted & Unadjusted & Adjusted & Unadjusted & Adjusted \\
\hline \multicolumn{7}{|l|}{ Body mass index } \\
\hline$<25 \mathrm{~kg} / \mathrm{m}^{2}$ & 0.0 (referent) & 0.0 (referent) & 0.0 (referent) & 0.0 (referent) & 0.0 (referent) & 0.0 (referent) \\
\hline$\geq 25,<30 \mathrm{~kg} / \mathrm{m}^{2}$ & $-0.8(-1.3,-0.3)$ & $-0.7(-1.2,-0.3)$ & $-1.5(-2.0,-1.0)$ & $-1.4(-1.9,-1.0)$ & $2.3(1.5,3.2)$ & $2.2(1.4,3.0)$ \\
\hline$\geq 30,<35 \mathrm{~kg} / \mathrm{m}^{2}$ & $-1.8(-2.3,-1.3)$ & $-1.6(-2.0,-1.1)$ & $-3.1(-3.6,-2.6)$ & $-2.8(-3.3,-2.3)$ & $4.9(4.0,5.7)$ & $4.3(3.5,5.1)$ \\
\hline$\geq 35$ & $-2.3(-2.8,-1.7)$ & $-1.7(-2.2,-1.2)$ & $-4.8(-5.4,-4.3)$ & $-4.0(-4.5,-3.5)$ & $7.1(6.2,8.0)$ & $5.7(4.8,6.5)$ \\
\hline $\mathrm{P}$ for trend & $<0.001$ & $<0.001$ & $<0.001$ & $<0.001$ & $<0.001$ & $<0.001$ \\
\hline \multicolumn{7}{|l|}{$\%$ Body fat } \\
\hline Quartile 1 & 0.0 (referent) & 0.0 (referent) & 0.0 (referent) & 0.0 (referent) & 0.0 (referent) & 0.0 (referent) \\
\hline Quartile 2 & $-0.6(-1.1,-0.2)$ & $-0.6(-1.0,-0.2)$ & $-1.2(-1.7,-0.8)$ & $-1.1(-1.6,-0.7)$ & $1.9(1.1,2.7)$ & $1.7(1.0,2.4)$ \\
\hline Quartile 3 & $-0.9(-1.4,-0.5)$ & $-0.8(-1.2,-0.4)$ & $-1.9(-2.4,-1.4)$ & $-1.7(-2.1,-1.2)$ & $2.8(2.1,3.6)$ & $2.5(1.8,3.2)$ \\
\hline Quartile 4 & $-1.2(-1.6,-0.7)$ & $-1.2(-1.6,-0.7)$ & $-3.0(-3.4,-2.5)$ & $-2.6(-3.1,-2.2)$ & $4.1(3.4,4.9)$ & $3.8(3.1,4.5)$ \\
\hline $\mathrm{P}$ for trend & $<0.001$ & $<0.001$ & $<0.001$ & $<0.001$ & $<0.001$ & $<0.001$ \\
\hline \multicolumn{7}{|l|}{ Fat free mass } \\
\hline Quartile 1 & 0.0 (referent) & 0.0 (referent) & 0.0 (referent) & 0.0 (referent) & 0.0 (referent) & 0.0 (referent) \\
\hline Quartile 2 & $-0.8(-1.2,-0.3)$ & $-0.8(-1.2,-0.4)$ & $-1.2(-1.7,-0.7)$ & $-1.2(-1.7,-0.8)$ & $2.0(1.2,2.7)$ & $2.0(1.3,2.7)$ \\
\hline Quartile 3 & $-0.6(-1.1,-0.2)$ & $-0.7(-1.1,-0.2)$ & $-1.5(-2.0,-1.1)$ & $-1.6(-2.0,-1.1)$ & $2.2(1.4,2.9)$ & $2.2(1.5,2.9)$ \\
\hline Quartile 4 & $-1.5(-1.9,-1.0)$ & $-1.4(-1.9,-1.0)$ & $-2.9(-3.4,-2.5)$ & $-2.8(-3.3,-2.3)$ & $4.4(3.6,5.2)$ & $4.2(3.5,5.0)$ \\
\hline $\mathrm{P}$ for trend & $<0.001$ & $<0.001$ & $<0.001$ & $<0.001$ & $<0.001$ & $<0.001$ \\
\hline \multicolumn{7}{|l|}{ Waist circumference } \\
\hline Quartile 1 & 0.0 (referent) & 0.0 (referent) & 0.0 (referent) & 0.0 (referent) & 0.0 (referent) & 0.0 (referent) \\
\hline Quartile 2 & $-0.8(-1.2,-0.3)$ & $-0.8(-1.2,-0.4)$ & $-1.2(-1.7,-0.7)$ & $-1.2(-1.7,-0.8)$ & $2.0(1.2,2.8)$ & $2.0(1.3,2.7)$ \\
\hline Quartile 3 & $-1.2(-1.7,-0.8)$ & $-1.2(-1.6,-0.8)$ & $-2.3(-2.7,-1.8)$ & $-2.2(-2.6,-1.7)$ & $3.5(2.7,4.2)$ & $3.3(2.6,4.1)$ \\
\hline Quartile 4 & $-1.6(-2.0,-1.2)$ & $-1.6(-2.1,-1.2)$ & $-3.4(-3.9,-3.0)$ & $-3.2(-3.6,-2.7)$ & $5.0(4.3,5.8)$ & $4.8(4.1,5.5)$ \\
\hline P for trend & $<0.001$ & $<0.001$ & $<0.001$ & $<0.001$ & $<0.001$ & $<0.001$ \\
\hline
\end{tabular}

Adjusted linear regression models control for age, sex, specific gravity-corrected arsenic, education, and drinking and smoking status. Quartiles for waist circumference, \% body fat and fat free mass use sex-specific cutpoints.

(Figure 1, Additional file 3: Appendix 3). Both generalized gamma and beta regression models allowed us to evaluate differences in \% arsenic species variability with increasing body mass index, showing that variability decreased with increasing body mass index categories (Figure 1). The shift of the population to more \%DMA and less heterogeneity across individuals with increasing body mass index was also apparent from the multivariate Dirichlet analysis of all \% arsenic species biomarkers (Figure 2). Results for each biomarker's relationship with body mass index were similar in univariate beta regression and multivariate Dirichlet regression (Additional file 3: Appendix 3).

\section{Conclusion}

Body mass index, \% body fat, fat free mass and waist circumference were associated with lower \%iAs, lower \%MMA, and higher \%DMA in urine of the Strong Heart Study participants. The associations remained similar after adjustment for age, sex, study center, education, drinking status, smoking status and urine arsenic levels. In analyses that adjusted for other measures of body composition, body mass index remained associated with \% arsenic species while waist circumference remained associated when adjusted for \% body fat or fat free mass but not when adjusted for body mass index. These findings indicate that body size is associated with \% arsenic species, with higher body size being related to higher \% DMA in urine. It is unclear, however, if the associations observed are due to adiposity, fat free mass, body size, or some other construct. Information bias from measurement error and correlation across body composition variables could explain the findings of models that adjust for multiple body composition variables. At first glance, the results of Table 4 might be interpreted as an indication that body size, as measured by body mass index, rather than adiposity or fat free mass, is what drives the association with arsenic metabolism. However, body mass index is likely the most precisely measured measure of body composition of those evaluated in this study, followed by waist circumference [53], which in turn is likely more precise than the two 
Table 4 Difference $(95 \% \mathrm{Cl})$ of \% arsenic species in urine by one unit increase in body composition measure categories in unadjusted models and in models adjusted for other measures of body composition

\begin{tabular}{|c|c|c|c|c|c|c|c|c|}
\hline & \multicolumn{4}{|c|}{$\%$ MMA by } & \multicolumn{4}{|c|}{$\%$ DMA by } \\
\hline & BMI & $\%$ body fat & fat free mass & WC & BMI & $\%$ body fat & fat free mass & WC \\
\hline \multicolumn{9}{|l|}{ Unadjusted models } \\
\hline Measure & $-1.6(-1.8,-1.4)$ & $-1.0(-1.1,-0.8)$ & $-0.9(-1.1,-0.8)$ & $-1.1(-1.3,-1.0)$ & $2.4(2.1,2.6)$ & $1.3(1.1,1.6)$ & $1.3(1.1,1.6)$ & $1.7(1.4,1.9)$ \\
\hline \multicolumn{9}{|c|}{ Models with multiple body composition measures } \\
\hline BMI, \% body fat & $-1.8(-2.0,-1.5)$ & $0.2(0.0,0.4)$ & - & - & $2.7(2.4,3.1)$ & $-0.4(-0.8,-0.1)$ & - & - \\
\hline BMI, fat free & $-1.7(-1.9,-1.5)$ & - & $0.1(-0.1,0.3)$ & - & $2.5(2.1,2.9)$ & - & $-0.2(-0.5,0.2)$ & - \\
\hline BMI, WC & $-1.7(-1.9,-1.4)$ & - & - & $0.1(-0.2,0.3)$ & $2.5(2.1,3.0)$ & - & - & $-0.2(-0.6,0.2)$ \\
\hline$\%$ Fat, fat free & - & $-0.7(-0.9,-0.6)$ & $-0.7(-0.8,-0.5)$ & - & - & $1.0(0.7,1.2)$ & $1.0(0.7,1.2)$ & - \\
\hline$\%$ Fat, WC & - & $-0.3(-0.5,-0.1)$ & - & $-0.9(-1.1,-0.7)$ & - & $0.4(0.0,0.7)$ & - & $1.4(1.1,1.7)$ \\
\hline BMI, \% fat, fat free & $-1.9(-2.2,-1.6)$ & $0.2(0.0,0.5)$ & $0.1(-0.1,0.4)$ & - & $3.0(2.5,3.5)$ & $-0.5(-0.9,-0.2)$ & $-0.3(-0.6,0.0)$ & - \\
\hline BMI, \% fat, WC & $-1.8(-2.1,-1.5)$ & $0.2(0.0,0.4)$ & - & $0.0(-0.3,0.3)$ & $2.8(2.3,3.2)$ & $-0.4(-0.8,-0.1)$ & - & $0.0(-0.4,0.4)$ \\
\hline$\%$ fat, fat free, WC & - & $-0.4(-0.6,-0.2)$ & $-0.4(-0.6,-0.2)$ & $-0.6(-0.9,-0.4)$ & - & $0.5(0.1,0.8)$ & $0.6(0.2,0.9)$ & $1.0(0.6,1.4)$ \\
\hline All & $-1.9(-2.2,-1.5)$ & $0.3(0.0,0.5)$ & $0.2(-0.1,0.4)$ & $-0.1(-0.3,0.2)$ & $3.0(2.4,3.5)$ & $-0.6(-1.0,-0.2)$ & $-0.3(-0.7,0.0)$ & $0.1(-0.3,0.6)$ \\
\hline
\end{tabular}

BMI: body mass index; WC: waist circumference

Body composition measures were categorized as in Table 3 and entered into the model as ordinal. 

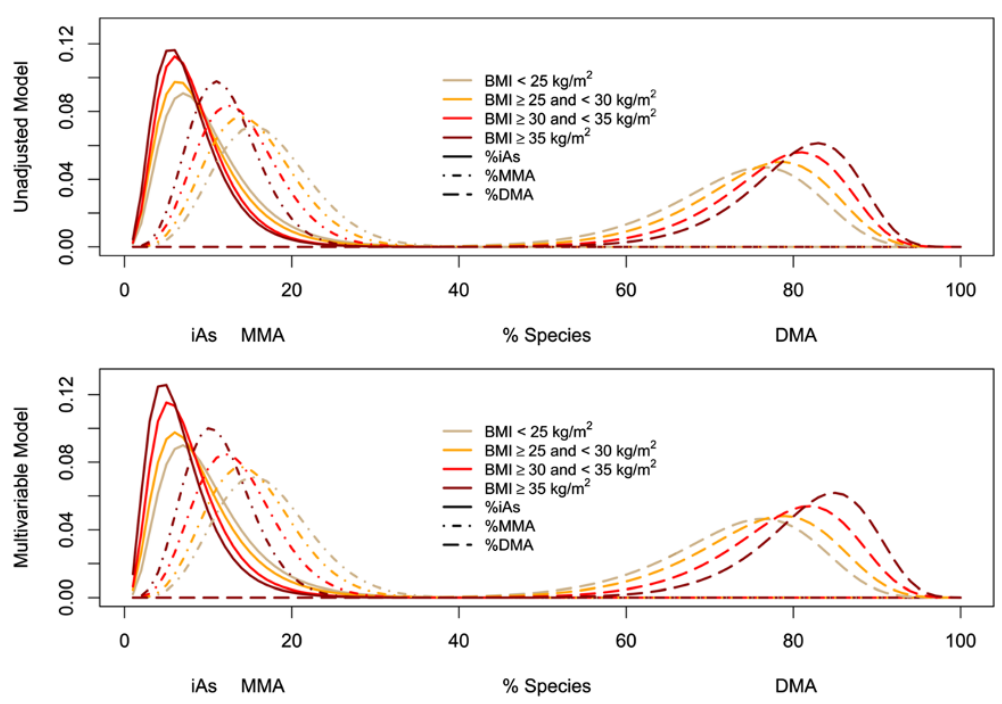

Figure 1 Maximum likelihood estimates of generalized gamma models for $\%$ arsenic species by body composition measures. The upper panel shows the crude associations of each \% species with body mass index categories. The lower panel shows the residual association adjusting for categories of other body composition measures. Models allowed flexibility in location ( $\beta$ ) and scale ( $\sigma$ ). The \% arsenic species are labeled at the marginal medians for each arsenic species.

measures obtained from impedance, $\%$ fat mass and fat free mass [54]. In multivariable models, it is possible to transfer the association from a casual exposure to a better measured co-exposure that is not necessarily causally related to the outcome when there are positive correlation in exposures' true values but negative correlations in measurement errors [55]. Thus, it is plausible that the consistently strong associations found with body mass index may be due to body mass index acting as a "sponge" for associations with other variables. To further disentangle the association of body composition measures with arsenic metabolism, it would be helpful to have multiple measures from the same visit of body mass index, \% body fat, fat free mass and waist circumference to obtain estimates of the test-retest reliability of each measure in this population and more explicitly model the measurement error dependence.
Despite the challenges posed by measurement error for understanding the etiologic basis for the association, body mass index was cross-sectionally associated with the pattern of arsenic metabolites in urine. This association might be related to adiposity. Previous studies have shown that \%DMA increases as women progress through pregnancy $[56,57]$. While the shifts are similar to those observed with increased body size in our study, it is unknown if those changes in arsenic metabolism during pregnancy are related to the concomitant gain in maternal body fat and body size [58,59]. Arsenic has been related to adiposity and to adipocyte differentiation in experimental models [60-63], although to our knowledge the roles of arsenic metabolism processes have not been evaluated. The association between body mass index and \% arsenic metabolites may also be related to muscle mass. Creatinine, a breakdown product of creatine phosphate in muscle is generally

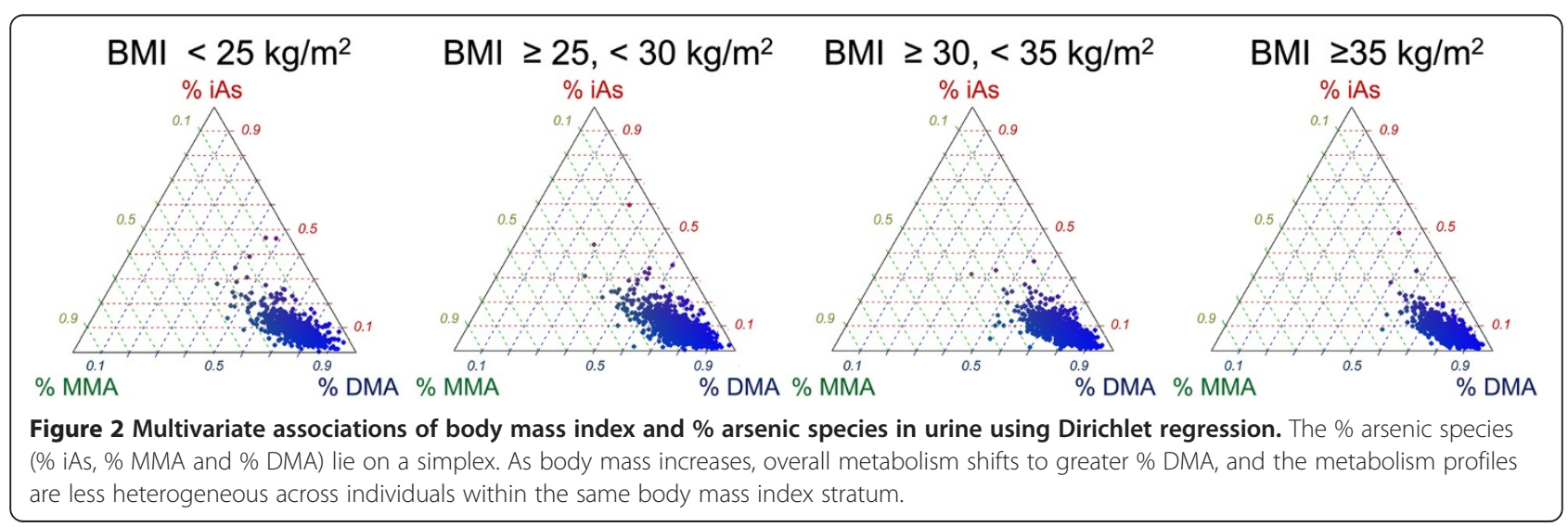


produced at a constant rate depending on muscle mass [64]. Creatinine may be a surrogate for several key mediators of the arsenic metabolism process as both arsenic metabolism [65] and creatine synthesis [66] use S-adenosyl methionine (SAM) as the methyl-donor. During methylation, SAM generates homocysteine which needs to be remethylated using folate and vitamin B12 [67] in order to be used again for methylation. Alternatively, homocysteine may form glutathione which is also important for arsenic species reduction and cellular efflux $[67,68]$. Experimental models are needed to evaluate if the connection between arsenic metabolism and measures of body composition are related to adiposity or to muscle mass.

We also found that those with higher body mass index had less variability in their distribution of \%DMA than those with lower body mass index. To our knowledge this has never been explicitly discussed in previous studies. However, this same pattern is visible in published histograms of \%DMA compared over the development of pregnancy [56,57]. It has been shown that as women progress through pregnancy, they have higher \%DMA in urine and more peaked distributions of \%DMA [56,57], much like the patterns seen across body size groups in our study. We suspect that the reduced variability with increasing adiposity or with the progression of pregnancy may reflect a constraint on maximum possible \%DMA. It would be interesting to evaluate if the pattern observed during pregnancy is related to increased adiposity.

Our study has a number of strengths and limitations. Strengths include the large sample size, multiple measures of body size, and the laboratory techniques for arsenic speciation, characterized by low limits of detection. Similar to other studies on arsenic metabolism, we are limited by the absence of data on arsenic species intake and routes of exposure. However, it is likely that the primary arsenic exposure for our population is inorganic arsenic from drinking water and that MMA and DMA observed in urine are mainly from metabolized inorganic arsenic [49]. The lack of data on arsenic species concentrations within the body, for instance in blood or adipose tissue, also limits pharmacokinetic inferences. This is a cross-sectional study, and the direction of the association is uncertain. Study designs with longitudinal data might enable evaluating the direction of the association and the impact of changes in body mass index in arsenic metabolism. Genetic advances characterizing arsenic metabolism could potentially enable Mendelian randomization studies of arsenic metabolism and adiposity [69]. Unmeasured confounding is possible. However, since these are large-magnitude associations, the unmeasured variables would need to be highly aliased with body size and with arsenic metabolite proportions to explain the observed associations. Fat-soluble chemicals for instance are strongly related to adiposity, but their relationship to arsenic metabolism is unknown.

\section{Conclusions}

Body mass index was associated with arsenic metabolite distributions in urine even after adjustment for other measures of body composition. These findings suggest that increased body size is related to higher \% DMA in urine, although we could not reach firm conclusions whether the association with body mass index is related to adiposity or fat free body mass, due to the potential impact of measurement error in models with multiple measures of body composition. Potentially, the association with body mass index could also be related to body size per se, rather than only adiposity or fat free mass. Experimental research can potentially advance our understanding of the relationship between body composition and arsenic metabolism. Prospective epidemiologic studies are also needed to evaluate the direction of the relationship between arsenic metabolism and body mass index. Inter-individual differences in arsenic metabolism may be important for population-level variation in arsenic susceptibility. Given the association between body mass index and arsenic metabolism, epidemiologic studies of arsenic health effects should examine whether body mass index may be a modifier of arsenic disease risks.

\section{Additional files}

Additional file 1: Appendix 1. Strong Heart Study population and analysis sample.

Additional file 2: Appendix 2. Histograms of $\%$ arsenic species. The solid line over each histogram represents the maximum likelihood estimate of the corresponding generalized gamma model.

Additional file 3: Appendix 3. Difference $(95 \% \mathrm{Cl})$ of mean $\%$ arsenic species in urine by body mass index categories using beta and Dirichlet regression models. Models for each separate \% arsenic species biomarker allowed for flexibility in mean $(\mu)$ and dispersion $(\varphi)$ parameters according to categories of body mass index.

\section{Abbreviations}

BMI: Body mass index; iAs: Inorganic arsenic; MMA: Methylarsonate (a methylated arsenic species); DMA: Dimethylarsinate (a methylated arsenic species); \%iAs: Proportion of inorganic arsenic contributing to sum iAs + MMA + DMA in urine; \%MMA: Proportion of methylarsonate contributing to sum iAs + MMA + DMA in urine; \%DMA: Proportion of dimethylarsinate contributing to sum iAs + MMA + DMA in urine; SAM: S-adenosyl methionine.

\section{Competing interests}

The authors declare that they have no competing interests.

\section{Author's contributions}

MOG drafted the manuscript, conducted statistical analyses, and contributed to the discussion. BVH, JGU, and YZ provided data, edited the manuscript and contributed to the discussion. KAF and WG conducted laboratory analyses, edited the manuscript and contributed to the discussion. CMC and YZ provided statistical support and contributed to the discussion. EKS and EG edited the manuscript and contributed to the discussion. ANA drafted the manuscript, supervised statistical analyses, and contributed to the discussion. All authors read and approved the final manuscript.

\section{Acknowledgements}

Supported by grants from the National Heart Lung and Blood Institute (R01HL090863 and by SHS grants HL41642, HL41652, HL41654 and 
HL65521) and the National Institute for Environmental Health Sciences (R01ES021367 and P30ES03819). M. Gribble was supported by T32 training grants from the National Heart, Lung, and Blood Institute (5T32HL007024) and the National Institute of Diabetes and Digestive and Kidney Diseases (5T32DK062707-10). Matthew Gribble and Ana Navas-Acien are the guarantors of the manuscript and take responsibility for the work as a whole.

\section{Author details}

'Department of Epidemiology and Welch Center for Prevention, Epidemiology and Clinical Research, Johns Hopkins University Bloomberg School of Public Health, 615 N. Wolfe Street Office W7513D, Baltimore MD 21205MD, USA. Department of Biostatistics, Johns Hopkins University Bloomberg School of Public Health, Baltimore, MD, USA. ${ }^{3}$ MedStar Health Research Institute, Hyattsville, MD, USA. ${ }^{4}$ Georgetown-Howard Universities Center for Clinical and Translational Science, Washington DC, USA. ${ }^{5}$ Institute of Chemistry - Analytical Chemistry, Karl-Franzens University Graz, Graz, Austria. ${ }^{6}$ University of Oklahoma Health Sciences Center, Oklahoma City, OK, USA. ${ }^{7}$ Department of Environmental Health Sciences, Johns Hopkins University Bloomberg School of Public Health, Baltimore, MD, USA. ${ }^{8}$ Department of Medicine, Johns Hopkins Medical Institutions, Baltimore, MD, USA.

Received: 2 July 2013 Accepted: 3 December 2013

Published: 9 December 2013

\section{References}

1. IARC: Some Drinking-Water Disinfectants and Contaminants, including Arsenic. In IARC Monographs on the Evaluation of Carcinogenic Risks to Humans. vol. 84. Lyon, France: WHO Press; 2004.

2. Schoof RA, Yost LJ, Eickhoff J, Crecelius EA, Cragin DW, Meacher DM, Menzel DB: A market basket survey of inorganic arsenic in food. Food Chem Toxicol 1999, 37:839-846.

3. Calderon RL, Hudgens E, Le XC, Schreinemachers D, Thomas DJ: Excretion of arsenic in urine as a function of exposure to arsenic in drinking water. Envi Health Perspect 1999, 107:663-667.

4. Nordstrom DK: Worldwide Occurrences of Arsenic in Ground Water. Science 2002, 296:2143-2145.

5. Smedley PL, Kinniburgh DG: A review of the source, behaviour and distribution of arsenic in natural waters. App/ Geochem 2002, 17:517-568.

6. Vahter M: Mechanisms of arsenic biotransformation. Toxicology 2002, 181-182:211-217.

7. Hopenhayn-Rich C, Biggs ML, Smith AH, Kalman DA, Moore LE: Methylation study of a population environmentally exposed to arsenic in drinking water. Envi Health Perspect 1996, 104:620-628.

8. Chiou HY, Hsueh YM, Hsieh LL, Hsu LI, Hsu YH, Hsieh Fl, Wei ML, Chen HC, Yang HT, Leu LC, Chu TH, Chen-Wu C, Yang MH, Chen CJ: Arsenic methylation capacity, body retention, and null genotypes of glutathione S-transferase M1 and T1 among current arsenic-exposed residents in Taiwan. Mutat Res 1997, 386:197-207.

9. Gamble MV, Liu X: Urinary creatinine and arsenic metabolism. Envi Health Perspect 2005, 113:A442-A443. A442; author reply.

10. Gomez-Rubio P, Roberge J, Arendell L, Harris RB, O'Rourke MK, Chen Z Cantu-Soto E, Meza-Montenegro MM, Billheimer D, Lu Z, Klimecki WT: Association between body mass index and arsenic methylation efficiency in adult women from southwest U.S. and northwest Mexico. Toxicol Appl Pharmacol 2011, 252:176-82.

11. Navas-Acien A, Umans JG, Howard BV, Goessler W, Francesconi KA Crainiceanu CM, Silbergeld EK, Guallar E: Urine arsenic concentrations and species excretion patterns in American Indian communities over a 10-year period: the Strong Heart Study. Envi Health Perspect 2009, 117:1428-1433.

12. Vahter M: Genetic polymorphism in the biotransformation of inorganic arsenic and its role in toxicity. Toxicol Lett 2000, 112-113:209-217.

13. Ahsan H, Chen Y, Kibriya MG, Slavkovich V, Parvez F, Jasmine F, Gamble MV, Graziano $\mathrm{JH}$ : Arsenic metabolism, genetic susceptibility, and risk of premalignant skin lesions in Bangladesh. Cancer Epid Bio Prev 2007, 16:1270-1278

14. Chen Y, Parvez F, Gamble M, Islam T, Ahmed A, Argos M, Graziano JH, Ahsan $\mathrm{H}$ : Arsenic exposure at low-to-moderate levels and skin lesions, arsenic metabolism, neurological functions, and biomarkers for respiratory and cardiovascular diseases: review of recent findings from the Health
Effects of Arsenic Longitudinal Study (HEALS) in Bangladesh. Toxicol Appl Pharmacol 2009, 239:184-192

15. Valenzuela OL, Drobna Z, Hernandez-Castellanos E, Sanchez-Pena LC, Garcia-Vargas GG, Borja-Aburto VH, Styblo M, Del Razo LM: Association of AS3MT polymorphisms and the risk of premalignant arsenic skin lesions. Toxicol Appl Pharmacol 2009, 239:200-207.

16. Steinmaus C, Bates MN, Yuan Y, Kalman D, Atallah R, Rey OA, Biggs ML, Hopenhayn C, Moore LE, Hoang BK, Smith AH: Arsenic methylation and bladder cancer risk in case-control studies in Argentina and the United States. J Occup Environ Med 2006, 48:478-488.

17. Agusa T, Kunito T, Kubota R, Inoue S, Fujihara J, Minh TB, Ha NN, Tu NP, Trang PT, Chamnan C, Takeshita H, Iwata H, Tuyen BC, Viet PH, Tana TS, Tanabe S: Exposure, metabolism, and health effects of arsenic in residents from arsenic-contaminated groundwater areas of Vietnam and Cambodia: a review. Rev Environ Health 2010, 25:193-220.

18. Chen YC, Guo YL, Su HJ, Hsueh YM, Smith TJ, Ryan LM, Lee MS, Chao SC, Lee JY, Christiani DC: Arsenic methylation and skin cancer risk in southwestern Taiwan. J Occup Environ Med 2003, 45:241-248.

19. Yu RC, Hsu KH, Chen CJ, Froines JR: Arsenic methylation capacity and skin cancer. Cancer Epi Bio Prev 2000, 9:1259-1262.

20. Steinmaus C, Yuan Y, Kalman D, Rey OA, Skibola CF, Dauphine D, Basu A Porter KE, Hubbard A, Bates MN, Smith MT, Smith AH: Individual differences in arsenic metabolism and lung cancer in a case-control study in Cordoba, Argentina. Toxicol Appl Pharmacol 2010, 247:138-145.

21. Huang YK, Huang YL, Hsueh YM, Yang MH, Wu MM, Chen SY, Hsu LI, Chen CJ: Arsenic exposure, urinary arsenic speciation, and the incidence of urothelial carcinoma: a twelve-year follow-up study. Cancer Causes Control 2008, 19:829-839.

22. Huang YK, Pu YS, Chung CJ, Shiue HS, Yang MH, Chen CJ, Hsueh YM: Plasma folate level, urinary arsenic methylation profiles, and urothelial carcinoma susceptibility. Food Chem Toxicol 2008, 46:929-938.

23. Huang YK, Tseng $\mathrm{CH}$, Huang YL, Yang MH, Chen CJ, Hsueh YM: Arsenic methylation capability and hypertension risk in subjects living in arseniasis-hyperendemic areas in southwestern Taiwan. Toxicol Appl Pharmacol 2007, 218:135-142

24. Huang YL, Hsueh YM, Huang YK, Yip PK, Yang MH, Chen CJ: Urinary arsenic methylation capability and carotid atherosclerosis risk in subjects living in arsenicosis-hyperendemic areas in southwestern Taiwan. Sci Total Environ 2009, 407:2608-2614.

25. Vahter M, Concha G: Role of metabolism in arsenic toxicity. Pharmacol Toxicol 2001, 89:1-5.

26. Drobna Z, Naranmandura H, Kubachka KM, Edwards BC, Herbin-Davis K, Styblo M, Le XC, Creed JT, Maeda N, Hughes MF, Thomas DJ: Disruption of the arsenic ( +3 oxidation state) methyltransferase gene in the mouse alters the phenotype for methylation of arsenic and affects distribution and retention of orally administered arsenate. Chem Res Toxicol 2009, 22:1713-1720

27. Drobna Z, Waters SB, Walton FS, LeCluyse EL, Thomas DJ, Styblo M: Interindividual variation in the metabolism of arsenic in cultured primary human hepatocytes. Toxicol Appl Pharmacol 2004, 201:166-177.

28. Hirano S, Cui X, Li S, Kanno S, Kobayashi Y, Hayakawa T, Shraim A: Difference in uptake and toxicity of trivalent and pentavalent inorganic arsenic in rat heart microvessel endothelial cells. Arch Toxicol 2003, 77:305-312.

29. Medina-Diaz IM, Estrada-Muniz E, Reyes-Hernandez OD, Ramirez P, Vega L, Elizondo G: Arsenite and its metabolites, MMA(III) and DMA(III), modify CYP3A4, PXR and RXR alpha expression in the small intestine of CYP3A4 transgenic mice. Toxicol Appl Pharmacol 2009, 239:162-168.

30. Kligerman $A D$, Doerr $C L$, Tennant $A H$ : Oxidation and methylation status determine the effects of arsenic on the mitotic apparatus. Mol Cell Biochem 2005, 279:113-121

31. Hirano S, Kobayashi Y, Cui X, Kanno S, Hayakawa T, Shraim A: The accumulation and toxicity of methylated arsenicals in endothelial cells: important roles of thiol compounds. Toxicol Appl Pharmacol 2004, 198:458-467.

32. Hernandez A, Marcos R: Genetic variations associated with interindividual sensitivity in the response to arsenic exposure. Pharmacogenomics 2008, 9:1113-1132.

33. Wood TC, Salavagionne OE, Mukherjee B, Wang L, Klumpp AF, Thomae BA, Eckloff BW, Schaid DJ, Wieben ED, Weinshilboum RM: Human arsenic methyltransferase (AS3MT) pharmacogenetics: gene resequencing and functional genomics studies. J Biol Chem 2006, 281:7364-7373. 
34. Thomas DJ, Li J, Waters SB, Xing W, Adair BM, Drobna Z, Devesa V, Styblo M: Arsenic ( +3 oxidation state) methyltransferase and the methylation of arsenicals. Exp Biol Med (Maywood) 2007, 232:3-13.

35. Drobna Z, Styblo M, Thomas DJ: Manipulation of expression of arsenic (+3 oxidation state) methyltransferase in cultured cells. Curr Protoc Toxicol 2010, 4:4-35.

36. Tseng $\mathrm{CH}$ : A review on environmental factors regulating arsenic methylation in humans. Toxicol Appl Pharmacol 2009, 235:338-350.

37. Hall MN, Liu X, Slavkovich V, Ilievski V, Pilsner JR, Alam S, Factor-Litvak P, Graziano JH, Gamble MV: Folate, cobalamin, cysteine, homocysteine, and arsenic metabolism among children in Bangladesh. Environ Health Perspect 2009, 117:825-831.

38. Lindberg AL, Kumar R, Goessler W, Thirumaran R, Gurzau E, Koppova K, Rudnai $P$, Leonardi G, Fletcher T, Vahter M: Metabolism of low-dose inorganic arsenic in a central European population: influence of sex and genetic polymorphisms. Environ Health Perspect 2007, 115:1081-1086.

39. Heck JE, Gamble MV, Chen Y, Graziano JH, Slavkovich V, Parvez F, Baron JA Howe GR, Ahsan $\mathrm{H}$ : Consumption of folate-related nutrients and metabolism of arsenic in Bangladesh. Am J Clin Nutr 2007, 85:1367-1374.

40. Kile ML, Hoffman E, Hsueh YM, Afroz S, Quamruzzaman Q, Rahman M, Mahiuddin G, Ryan L, Christiani DC: Variability in biomarkers of arsenic exposure and metabolism in adults over time. Environ Health Perspect 2009, 117:455-460.

41. Su CT, Lin HC, Choy CS, Huang YK, Huang SR, Hsueh YM: The relationship between obesity, insulin and arsenic methylation capability in Taiwan adolescents. Sci Total Environ 2012, 414:152-158.

42. Stevens J, McClain JE, Truesdale KP: Selection of measures in epidemiologic studies of the consequences of obesity. Int J Obes (Lond) 2008, 32(Suppl 3):S60-S66.

43. Lee ET, Welty TK, Fabsitz R, Cowan LD, Le NA, Oopik AJ, Cucchiara AJ, Savage PJ, Howard BV: The Strong Heart Study. A study of cardiovascular disease in American Indians: design and methods. Am J Epidemiol 1990, 132:1141-1155.

44. The Strong Heart Study manual: chapter 5: clinical examination. Modified May 2, 2003. 2012. http://strongheart.ouhsc.edu/manual/Phasel/ Chapter\%205.pdf.

45. Jones MR, Tellez-Plaza M, Sharrett AR, Guallar E, Navas-Acien A: Urine arsenic and hypertension in US adults: the 2003-2008 national health and nutrition examination survey. Epidemiology 2011, 22:153-161.

46. Rising R, Swinburn B, Larson K, Ravussin E: Body composition in Pima Indians: validation of bioelectrical resistance. Am J Clin Nutr 1991, 53:594-598.

47. Stolarczyk LM, Heyward VH, Hicks VL, Baumgartner RN: Predictive accuracy of bioelectrical impedance in estimating body composition of Native American women. Am J Clin Nutr 1994, 59:964-970.

48. Scheer J, Findenig S, Goessler W, Francesconi K, Howard B, Umans J, Pollak J, Tellez-Plaza M, Silbergeld E, Guallar E, Navas-Acien A: Arsenic species and selected metals in human urine: validation of HPLC/ICPMS and ICPMS procedures for a long-term population-based epidemiological study. Analytical Methods 2012, 4:406-413.

49. Gribble MO, Howard BV, Umans JG, Shara NM, Francesconi KA, Goessler W, Crainiceanu CM, Silbergeld EK, Guallar E, Navas-Acien A: Arsenic exposure, diabetes prevalence, and diabetes control in the Strong Heart Study. Am J Epidemiol 2012, 176:865-874.

50. Cox C, Chu H, Schneider MF, Munoz A: Parametric survival analysis and taxonomy of hazard functions for the generalized gamma distribution. Stat Med 2007, 26:4352-4374.

51. Ferrari SL, Cribari-Neto F: Beta regression for modelling rates and proportions. J App/ Stat 2004, 31:799-815.

52. Hijazi RH, Jernigan RW: Modelling compositional data using Dirichlet regression models. J Appl Probab Stat 2009, 4:77-91.

53. Klipstein-Grobusch K, Georg T, Boeing H: Interviewer variability in anthropometric measurements and estimates of body composition. Int J Epidemiol 1997, 26(Suppl 1):S174-S180.

54. Bioelectrical impedance analysis in body composition measurement: National Institutes of Health Technology Assessment Conference Statement. Am J Clin Nutr 1996, 64:524S-532S.

55. Zeger SL, Thomas D, Dominici F, Samet JM, Schwartz J, Dockery D, Cohen A: Exposure measurement error in time-series studies of air pollution: concepts and consequences. Environ Health Perspect 2000, 108:419-426.

56. Gardner RM, Nermell B, Kippler M, Grander M, Li L, Ekstrom EC, Rahman A, Lonnerdal B, Hoque AM, Vahter M: Arsenic methylation efficiency increases during the first trimester of pregnancy independent of folate status. Reprod Toxicol 2011, 31:210-218.

57. Hopenhayn C, Huang B, Christian J, Peralta C, Ferreccio C, Atallah R, Kalman D: Profile of urinary arsenic metabolites during pregnancy.

Environ Health Perspect 2003, 111:1888-1891.

58. Butte NF, Ellis KJ, Wong WW, Hopkinson JM, Smith EO: Composition of gestational weight gain impacts maternal fat retention and infant birth weight. Am J Obstet Gynecol 2003, 189:1423-1432.

59. Lederman SA, Paxton A, Heymsfield SB, Wang J, Thornton J, Pierson RN Jr: Body fat and water changes during pregnancy in women with different body weight and weight gain. Obstet Gynecol 1997, 90:483-488.

60. Klei LR, Garciafigueroa DY, Barchowsky A: Arsenic activates endothelin-1 gi protein-coupled receptor signaling to inhibit stem cell differentiation in adipogenesis. Toxicol Sci 2013, 131:512-520

61. Salazard B, Bellon L, Jean S, Maraninchi M, El-Yazidi C, Orsiere T, Margotat A Botta A, Berge-Lefranc JL: Low-level arsenite activates the transcription of genes involved in adipose differentiation. Cell Biol Toxicol 2004, 20:375-385.

62. Wauson EM, Langan AS, Vorce RL: Sodium arsenite inhibits and reverses expression of adipogenic and fat cell-specific genes during in vitro adipogenesis. Toxicol Sci 2002, 65:211-219.

63. Hou Y, Xue P, Woods CG, Wang X, Fu J, Yarborough K, Qu W, Zhang Q, Andersen ME, Pi J: Association between arsenic suppression of adipogenesis and induction of CHOP10 via the endoplasmic reticulum stress response. Environ Health Perspect 2013, 121:237-243.

64. Heymsfield SB, Arteaga C, McManus C, Smith J, Moffitt S: Measurement of muscle mass in humans: validity of the 24-hour urinary creatinine method. Am J Clin Nutr 1983, 37:478-494.

65. Loenen WA: S-adenosylmethionine: jack of all trades and master of everything? Biochem Soc Trans 2006, 34:330-333.

66. Brosnan JT, da Silva RP, Brosnan ME: The metabolic burden of creatine synthesis. Amino Acids 2011, 40:1325-1331.

67. Gamble MV, Hall MN: Relationship of creatinine and nutrition with arsenic metabolism. Environ Health Perspect 2012, 120:A145-A146.

68. Thomas DJ: Unraveling arsenic-glutathione connections. Toxicol Sci 2009, 107:309-311.

69. Lawlor DA, Harbord RM, Sterne JA, Timpson N, Davey Smith G: Mendelian randomization: using genes as instruments for making causal inferences in epidemiology. Stat Med 2008, 27:1133-1163.

doi:10.1186/1476-069X-12-107

Cite this article as: Gribble et al.: Body composition and arsenic metabolism: a cross-sectional analysis in the Strong Heart Study. Environmental Health 2013 12:107.

\section{Submit your next manuscript to BioMed Central and take full advantage of:}

- Convenient online submission

- Thorough peer review

- No space constraints or color figure charges

- Immediate publication on acceptance

- Inclusion in PubMed, CAS, Scopus and Google Scholar

- Research which is freely available for redistribution 